\title{
Personality Traits and Facebook Use: The Combined/Interactive Effect of Extraversion, Neuroticism and Conscientiousness
}

\author{
Louise La Sala, Jason Skues, Sharon Grant \\ Department of Psychological Sciences and Statistics, Swinburne University of Technology, Melbourne, Australia \\ Email: $\underline{\text { llasala@swin.edu.au }}$
}

Received 3 August 2014; revised 5 September 2014; accepted 2 October 2014

Copyright $@ 2014$ by authors and Scientific Research Publishing Inc.

This work is licensed under the Creative Commons Attribution International License (CC BY). http://creativecommons.org/licenses/by/4.0/

(c) (i) Open Access

\section{Abstract}

This study examined the influence of Big Five personality traits on Facebook usage and examined the interactions of traits in this context based on Torgersen's (1995) typological approach. The effect of self-esteem, narcissism, loneliness, shyness and boredom proneness on Facebook usage was also investigated. The sample included both student $(N=190)$ and $(N=184)$ non-student samples. Narcissism was the strongest predictor of time spent on Facebook per day for both students and non-students. Narcissism was also the strongest predictor of number of daily logins for non-students, however, agreeableness was the strongest predictor of logins for students. Extraversion was the strongest predictor of number of Facebook friends for both students and nonstudents, however the interaction of Extraversion and Neuroticism was also a predictor of Facebook friends for students, and the interaction of Extraversion and Conscientiousness for non-students. Future research should consider the combined effect of personality traits on overall Facebook use.

\section{Keywords}

Facebook, Personality, Five Factor Model, Psychological Characteristics, Narcissism, Boredom Proneness

\section{Introduction}

As the largest and most popular social networking site, Facebook has more than 750 million active users and is the second most visited website behind Google [1] [2]. Users typically spend from 10 minutes to more than two hours per day on Facebook [3] [4]. Given the rapid growth in Facebook use, it is important to understand more 
about who uses it and why.

The majority of studies on personality traits associated with Facebook use have relied on Costa and McCrae's [5], Five Factor Model (FFM) of personality as a guiding framework [2] [4] [6]-[8]. However, research on the "Big Five" traits and Facebook use has been equivocal. Some studies have found users high in Extraversion spend more time on Facebook [9] and have more Facebook friends [6], while others have failed to find an association between Extraversion and these variables [7]. Findings for Neuroticism and Openness have been equally mixed [2] [7]-[9], and agreeableness and Conscientiousness have received less attention. Most studies [6]-[8] have used Facebook usage indicators such as time spent per day and number of friends or photos, with the five individual traits alone explaining very little variance in these behaviors.

A limitation of the extant literature on personality and Facebook use is its analysis of individual personality traits in isolation and not combinations of traits. That is, examination of the effect of high and low scores on single traits (e.g., Extraversion) rather than high-low combinations of different traits simultaneously (e.g., high Extraversion, low Neuroticism). The current study examines the combined/interactive effect of Extraversion, Neuroticism and Conscientiousness in predicting Facebook use, based on Torgersen's typology [10].

Based on twin studies of personality disorders, Torgersen [10] specified eight types based on different highlow combinations of the hysterical (Extraversion), oral (Neuroticism) and obsessive (Conscientious) traits. Vollrath and Torgersen [11] argued that it is important to note that a person is not solely extraverted, conscientious or neurotic, but rather a simultaneous combination of these traits; the level of one trait may strengthen or weaken the relationship between another trait and criterion variables. The typology has been used primarily in stress and coping research, with some types emerging as more vulnerable than others [11]-[13]. Notably Openness and agreeableness have fewer and less consistent correlations with Facebook use, and Conscientiousness has been less explored than Extraversion and Neuroticism. A typology based on Extraversion, Neuroticism, and Conscientiousness was therefore proposed as a good fit for Facebook research.

Vollrath's types can be summarized as follows: spectators (low E, N, and C) who are emotionally flat, unambitious, disinterested in social norms and unresponsive to social cues/others; insecure (low E, high N, low C) who are shy, reserved, self-conscious, hypersensitive to mental and emotional experiences and dependent on the opinions of others; sceptics (low E, low N, high C) who are systematic, emotionally secure and do not have emotionally open relations with others; brooders (low E, high $\mathrm{N}$, high $\mathrm{C}$ ) who are socially withdrawn and shy, insecure and dwell on things, often leading them to give up under pressure; hedonists (high E, low N, low C) who are resilient, skilled socially and driven by feelings of pleasure; impulsives (high E, high N, low C) who are in constant need of social confirmation, attention seeking and lack emotional self-control; entrepreneurs (high E, low N, high C) who are goal-directed, self-secure and independent; and finally, complicated (high E, N, and C) who are socially dependent, sensitive and emotionally intense [11] [13].

Three of the eight types were expected to be particularly relevant to Facebook usage. As the spectators are often unresponsive to social cues and social norms, it was expected that they would be less likely to use Facebook to communicate with friends. To the extent that insecure types are more self-conscious and dependent on others' opinions, it was hypothesized that they would spend more time online and have more Facebook friends. Finally, it was hypothesized that impulsives, who are attention seeking and need social affirmation, login to Facebook more frequently, upload more photos and have more Facebook friends.

A further limitation in the Facebook literature has been the reliance on global Big Five factors to explain differences in Facebook use, with less focus on specific personality characteristics, which might better explain individual differences. Recently, Facebook behavior has been linked to self-esteem [1] [8] [9] [14], narcissism [2] [8] [15] [16], loneliness [2] [8] and shyness [17]. Wilson et al. [9] argued that self-esteem was unrelated to Facebook use, however other studies have found that low self-esteem is associated with more regular checking of profiles and more time spent online, potentially to compensate for a lack of offline social ties [1] [16]. Research has found users high on narcissism prefer to post photos of themselves and update their status frequently [2]. They also check their accounts more often and spend more time online [15] [16]. Loneliness is associated with more passive Facebook functions, spending more time online per day [2] and, in some cases, a greater number of Facebook friends [8]. Other research has found that shy students have fewer Facebook friends, spend more time online and have positive attitudes towards Facebook [17]. Although boredom has been identified as a potential predictor of Internet usage [18], relatively few, if any, studies have investigated the relationship between boredom proneness and Facebook use. Individuals may resort to Facebook to alleviate boredom [3].

The current study examines the effect of Big Five personality traits on Facebook use alongside other key 
variables in the Facebook or Internet use literature, namely self-esteem, narcissism, loneliness, shyness, and boredom proneness. Furthermore, since the majority of previous studies have focused on university students alone, a widely acknowledged limitation, this study includes both student and non-student samples concurrently. Thus, the aims of the current study were to 1) compare how university students versus non-students use Facebook; 2) examine how Torgersen's personality typology relates to Facebook use; and 3) examine the relationship between Facebook use and FFM personality traits, self-esteem, narcissism, loneliness, shyness and boredom proneness.

\section{Method}

\subsection{Participants}

The sample consisted of 374 participants (26.2\% men, $71.8 \%$ women, $2 \%$ did not specify gender) aged between 18 and 62 years $(M=26.59, S D=10.14)$; 95\% had a Facebook account. There were 190 university students (72.6\% women, $25.7 \%$ men) with a mean age of 21.67 years $(S D=4.24)$, and 184 non-students $(72.2 \%$ women, $27.1 \%$ men) with a mean age of 31.79 years $(S D=11.84)$.

\subsection{Measures}

\subsubsection{Australian Personality Inventory [19]}

This measure consists of 50 items from the International Personality Item Pool with ten items for each Big Five trait, Extraversion (e.g., “Am the life of the party”) and Neuroticism (e.g., “Often feel blue”), Conscientiousness (e.g., "Get chores done right away”), Agreeableness (e.g., "Respect others”), Openness (e.g., "Enjoy hearing new ideas"). Half of the items were reverse worded. Participants indicated their responses on a five-point Likert scale ranging from 1 (Very Inaccurate) to 5 (Very Accurate). After necessary reverse scoring, scores were summed and averaged for each trait. High scores indicate higher levels of each trait.

\subsubsection{Rosenberg's Self-Esteem Scale [20]}

This 10-item scale measures how people feel about themselves on a four-point scale ranging from 1 (Strongly Disagree) to 4 (Strongly Agree). Higher scores indicate higher self-esteem.

\subsubsection{Narcissism Personality Inventory-16-Item Version (NPI-16) [21]}

The NPI-16 is an abridged version of the NPI-40. Participants were asked to select the most appropriate response from a pair of items and responses were coded 0 (Narcissism-Inconsistent Responses) or 1 (NarcissismConsistent Responses). Higher scores indicate higher narcissism.

\subsubsection{UCLA Loneliness Scale Version 3 [22]}

This 20-item measure of loneliness has been found to be both reliable and valid among undergraduates. Participants indicated their responses on a four-point scale ranging from 1 (Never) to 4 (Always). Half of the items were reverse worded. After reverse scoring necessary items, scores were summed. Higher scores indicate higher loneliness.

\subsubsection{Boredom Proneness Scale [23]}

Participants were asked to indicate their responses to 28 items on a seven-point scale with responses ranging from 1 (Strongly Disagree) to 7 (Strongly Agree). After reverse scoring the necessary items, scores were summed. Higher scores indicate higher boredom proneness.

\subsubsection{Revised Cheek and Buss Shyness Scale (RCBS) [24]}

Participants responded to this 13-item measure on a 5-point Likert scale, ranging from 1 (Very Uncharacteristic or Untrue) to 5 (Very Characteristic or True). After reverse scoring the necessary items, scores were summed. Higher scores on this measure indicate higher shyness.

\subsubsection{Facebook Questionnaire-Adapted from Ross et al. [7]}

This 28-item questionnaire measures basic Facebook use, attitudes towards Facebook and posting of personal 
information on Facebook. General usage items gathered information about time spent online, number of friendships and group memberships, number of times an account is checked per day and preference for Facebook functionalities (e.g., photos, wall posts, instant messaging). A sample of an attitudinal item is "I feel out of touch when I haven’t logged into Facebook for a while”. Privacy and protection settings were also assessed.

\subsection{Procedure}

Ethical approval was secured and the research project was advertised via an undergraduate noticeboard, Facebook post, or email containing the URL for the questionnaire, and through snowball sampling. A Consent Information Statement outlined participant rights including voluntary consent, anonymity, and freedom to discontinue at any time and omit questions. The questionnaire was completed at a time and location convenient to participants and took approximately 30 minutes.

\section{Results}

All Facebook data collected were count data variables, which are variables that take on a number $(0,1,2 \ldots)$ and are presented only as a positive value [8] [25]. Count variables are typically positively skewed and violate assumptions of normality and homoscedascity. Thus, logarithmic transformations were used for all Facebook count variables [26]. Consistent with previous research [6]-[9], this study focuses on time spent on Facebook per day, number of logins per day and number of Facebook friends as outcome variables.

Of the sample, 79\% reported using Facebook everyday. Preferred Facebook functions across both student and non-student groups, were Photos (26\% of students and $29 \%$ of non-students), followed by the message feature (24\% of students) and the wall feature (19\% of non-students). Both students (55\%) and non-students (41\%) used Facebook to communicate with friends. The second most common reason for using Facebook among both students (12\%) and non-students (16\%) was communicating with people from one's past. A majority (85\% of students, $79 \%$ of non-students) regularly used Facebook on mobile phones, while $30 \%$ of students and $29 \%$ of nonstudents used it on SmartBooks. See Table 1 for means and standard deviations for study variables. Correlations between study variables for both populations are in Table 2 .

Table 1. Means and standard deviations of Facebook use for university students and non-students.

\begin{tabular}{ccccc}
\hline \multirow{2}{*}{ Variables } & \multicolumn{2}{c}{ Students $(N=190)$} & \multicolumn{2}{c}{ Non-students $(N=184)$} \\
\cline { 2 - 5 } Facebook Use & $M$ & $S D$ & \multicolumn{2}{c}{$S$} \\
Time (Daily) & 92.28 & 98.08 & 71.17 & 89.16 \\
Log in (Daily) & 7.02 & 8.16 & 5.39 & 5.11 \\
Friends & 437.01 & 287.94 & 349.17 & 331.54 \\
Photos & 512.49 & 628.63 & 407.63 & 534.69 \\
Groups & 29.15 & 118.22 & 19.93 & 91.89 \\
Psychological Variables & & & & \\
Neuroticism & 27.26 & 7.83 & 26.37 & 7.02 \\
Extraversion & 34.44 & 7.69 & 34.97 & 7.21 \\
Openness & 37.88 & 6.02 & 36.88 & 6.02 \\
Agreeableness & 37.73 & 5.32 & 37.63 & 5.87 \\
Conscientiousness & 35.26 & 6.47 & 36.27 & 6.49 \\
Shyness & 35.13 & 10.47 & 33.15 & 9.45 \\
Narcissism & 5.05 & 3.31 & 4.39 & 3.29 \\
Loneliness & 42.79 & 10.78 & 41.01 & 9.83 \\
Boredom proneness & 95.99 & 19.76 & 92.57 & 19.14 \\
Self-esteem & 30.32 & 6.63 & 31.86 & 5.39 \\
\hline
\end{tabular}


Table 2. Correlations between FFM traits, psychological variables and Facebook use for both students and non-students.

\begin{tabular}{|c|c|c|c|c|c|c|c|c|c|c|c|c|c|c|c|}
\hline & $\mathrm{N}$ & E & $\mathrm{O}$ & A & C & SHY & NARC & LONE & BORED & SE & TIME & LOGIN & FRIENDS & PHOTOS & GROUPS \\
\hline $\mathrm{N}$ & & $-0.24^{* *}$ & $-0.26^{* *}$ & $-0.29^{* *}$ & $-0.39^{* *}$ & $-0.37^{* *}$ & -0.04 & $0.57^{* *}$ & $0.55^{* *}$ & $-0.66^{* *}$ & $0.19^{*}$ & 0.10 & -0.00 & -0.02 & 0.04 \\
\hline E & $-0.32^{* *}$ & & $0.36^{* *}$ & 0.02 & $0.17^{*}$ & $-0.76^{* *}$ & $0.48^{* * *}$ & $-0.52^{* *}$ & $-0.35^{* *}$ & $0.38^{* *}$ & 0.09 & 0.14 & $0.39^{* *}$ & $0.30^{* *}$ & 0.10 \\
\hline $\mathrm{O}$ & 0.01 & $0.30^{* *}$ & & $0.20^{*}$ & 0.12 & $-0.28^{* *}$ & $0.26^{* *}$ & $-0.20^{* *}$ & $-0.31^{* *}$ & $0.26^{* *}$ & -0.08 & -0.08 & 0.01 & 0.04 & -0.02 \\
\hline A & $-0.31^{* *}$ & 0.12 & 0.09 & & $0.33^{* *}$ & -0.14 & $-0.35^{* *}$ & $-0.26^{* *}$ & $-0.39^{* *}$ & 0.12 & $-0.17^{*}$ & -0.07 & -0.15 & -0.08 & -0.13 \\
\hline $\mathrm{C}$ & $-0.36^{* *}$ & $0.26^{* *}$ & 0.10 & $0.29^{* *}$ & & $-0.25^{* *}$ & 0.03 & $-0.35^{* *}$ & $-0.56^{* *}$ & $0.46^{* *}$ & $-0.26^{* *}$ & -0.05 & $-0.17^{*}$ & -0.04 & $-0.19^{*}$ \\
\hline SHY & $0.42^{* *}$ & $-0.77^{* *}$ & $-0.23^{* *}$ & $-0.22^{* *}$ & $-0.25^{* *}$ & & $-0.32^{* *}$ & $0.63^{* *}$ & $0.41^{* *}$ & $-0.46^{* *}$ & -0.00 & 0.00 & $-0.23^{* *}$ & -0.14 & 0.05 \\
\hline NARC & $-0.19^{* *}$ & $0.50^{* *}$ & $0.23^{* *}$ & $-0.26^{* *}$ & 0.06 & $-0.42^{* *}$ & & -0.13 & -0.02 & $0.36^{* *}$ & $0.23^{* *}$ & $0.21^{* *}$ & $0.26^{* *}$ & 0.12 & 0.04 \\
\hline LONE & $0.61^{* *}$ & $-0.60^{* *}$ & -0.11 & $-0.27^{* *}$ & $-0.34^{* *}$ & $0.63^{* *}$ & $-0.26^{* *}$ & & $0.61^{* *}$ & $-0.64^{* *}$ & $0.16^{*}$ & 0.06 & -0.15 & -0.12 & 0.11 \\
\hline BORED & $0.56^{* *}$ & $-0.36^{* *}$ & $-0.23^{* *}$ & $-.47^{* *}$ & $-0.51^{* *}$ & $0.44^{* *}$ & -0.10 & $0.62^{* *}$ & & $-66^{* *}$ & $0.18^{*}$ & 0.08 & 0.05 & -0.04 & $0.23^{* *}$ \\
\hline SE & $-0.74^{* *}$ & $0.43^{* *}$ & 0.14 & $0.26^{* *}$ & $0.40^{* *}$ & $-0.45^{* *}$ & $0.29^{* *}$ & $-0.64^{* *}$ & $-0.61^{* *}$ & & -0.06 & -0.04 & -0.02 & 0.02 & -0.10 \\
\hline TIME & $0.19^{* *}$ & 0.08 & -0.10 & $-0.25^{* *}$ & $-0.16^{*}$ & -0.08 & $0.16^{*}$ & 0.02 & $0.21^{* *}$ & -0.11 & & $0.52^{* *}$ & $0.39^{* *}$ & $0.26^{* *}$ & $0.19^{*}$ \\
\hline LOGIN & 0.12 & $0.18^{*}$ & 0.02 & $-0.17^{*}$ & 0.00 & -0.00 & $0.21^{*}$ & -0.02 & 0.05 & -0.02 & $0.48^{* *}$ & & $0.32^{* *}$ & $0.52^{* *}$ & 0.16 \\
\hline FRIENDS & $-0.15^{*}$ & $0.45^{* *}$ & -0.06 & -0.04 & 0.04 & $-0.36^{* *}$ & $0.27^{* *}$ & $-0.26^{* *}$ & -0.06 & 0.12 & $0.18^{*}$ & $0.25^{* *}$ & & $0.56^{* *}$ & $0.36^{* *}$ \\
\hline PHOTOS & -0.06 & $0.38^{* *}$ & 0.05 & 0.01 & -0.04 & $-0.31^{* *}$ & $0.26^{* *}$ & $-0.31^{* *}$ & -0.08 & $0.17^{*}$ & 0.12 & $0.18^{*}$ & $0.50^{* *}$ & & $0.25^{* *}$ \\
\hline GROUPS & 0.06 & -0.01 & 0.03 & 0.09 & -0.01 & 0.05 & -0.07 & -0.01 & -0.02 & 0.00 & 0.11 & $0.17^{*}$ & 0.10 & $0.26^{* *}$ & \\
\hline
\end{tabular}

${ }^{*} p<0.05,{ }^{* *} p<0.01,{ }^{* * *} p<0.00, \mathrm{~N}=$ Neuroticism, $\mathrm{E}=$ Extraversion, $\mathrm{O}=$ Openness, $\mathrm{A}=$ Agreeableness, $\mathrm{C}=\mathrm{Conscientiousness,} \mathrm{SHY}=\mathrm{Shyness}, \mathrm{NARC}=$ Narcissism, LONE = Loneliness, BORED = Boredom Proneness, SE = Self Esteem, TIME = Time spent per day, LOGIN = Logins per day, FRIENDS = Number of of Facebook Friends, PHOTOS = Number of Facebook Photos, GROUPS = Number of Facebook Groups Items in boldface represent university students.

As shown in Table 1, mean time spent on Facebook daily and mean number of friends differed for students and non-students, $t(353)=2.42, p<0.05$ and $t(303.93)=3.84, p<0.01$ respectively. Students spent more time on Facebook and had more Facebook friends on average. Time spent on Facebook ranged from 5 to 720 minutes per day for students and 5 to 600 minutes per day for non-students. Number of logins and number of Facebook photos did not significantly differ. Students scored significantly lower on self-esteem than non-students, $t(372)=$ $2.45, p<0.05$.

Hierarchical regressions were performed with "time spent on Facebook per day", "number of logins per day" and "number of Facebook friends" as the dependent variables (DVs), and the FFM traits and the relevant interactions, and self-esteem, narcissism, loneliness, shyness and boredom proneness as the independent variables (IVs). Only IVs that were significantly correlated with the DVs at bivariate level were included in the regressions and these were entered at step 1. The two-way interactions (ExN, ExC, CxN; computed by multiplying mean-centered variables) were entered at step 2, and the three-way interaction (ExNxC) was entered at step 3 to investigate the effect of Vollrath's (1995) personality types. Student and non-student data were analysed separately.

Time spent on Facebook per day. The model for university students for Time spent on Facebook per day indicated that the combined predictors accounted for $14 \%$ of the variance, $R^{2}=0.14, F(9,184)=3.10, p<0.01$. The three-way interaction term failed to produce a significant increment in $R^{2}$ at step 3.

For non-students, the combined predictors accounted for $16 \%$ of the variance, $R^{2}=0.16, F(10,169)=2.96, p$ $<0.01$. Narcissism was the strongest predictor of time spent on Facebook per day explaining $6 \%$ in unique variance, followed by $3 \%$ for Conscientiousness. The variables as a set contributed a further $7 \%$ in shared variance. As with the previous model, the three-way interaction term failed to produce a significant increment in $R^{2}$.

Number of logins. With all the predictor variables in the regression equation for number of daily logins to Facebook per day for students, $R^{2}=0.10, F(7,183)=2.85, p<0.01$, indicating that the combined predictors accounted for $10 \%$ of the variance. Agreeableness was the strongest predictor explaining $2 \%$ in unique variance. The variables as a set contributed $8 \%$ in shared variance. Addition of the three-way interaction term at step 3 
failed to produce a significant increment in $R^{2}$.

With all predictor variables in the regression equation for number of daily logins to Facebook per day for non-students, $R^{2}=0.06, F(5,168)=2.09, p=0.07$. Narcissism was the only significant predictor of daily logins for non-students.

Number of Facebook friends. The regression equation for number of Facebook friends for students indicated that the combined predictors accounted for $24 \%$ of the variance, $R^{2}=0.24, F(9,181)=5.94, p<0.001$. Extraversion was the strongest predictor, explaining $6 \%$ in unique variance, followed by $3 \%$ explained by the two-way interaction between Neuroticism and Extraversion. The variables as a set contributed $15 \%$ in shared variance. Addition of the three-way interaction term at step 3 failed to produce a significant increment in $R^{2}$, however the interaction between Neuroticism and Extraversion was significant at step $2 \beta=0.16, t(173)=2.18$, $p<0.05$ and step $3, \beta=0.19, t(172)=2.50, p<0.05$. Although the set as a whole was non-significant, the interaction was plotted to explore whether the interaction effect was in the hypothesized direction.

As shown in Figure 1, those who were high in Extraversion and high in Neuroticism (impulsive and complicated types) tended to have more friends than those high in Neuroticism but low in Extraversion. This was consistent with expectations for the impulsive type. However, a simple slope analyses did not reveal a significant result.

The regression equation for number of Facebook friends for non-students indicated that the combined predictors accounted for $24 \%$ of the variance, $R^{2}$ was significantly different from zero, $R^{2}=0.24, F(8,169)=6.47, p$ $<0.001$. Extraversion was the strongest predictor, explaining $9 \%$ in unique variance, followed by $4 \%$ by Conscientiousness. The variables as a set contributed $11 \%$ in shared variance. Addition of the three-way interaction term at step 3 failed to produce a significant increment in $R^{2}$, however the interaction between Neuroticism and Conscientiousness was significant at step $2, \beta=0.20, t(162)=2.34, p<0.05$ and step $3, \beta=0.20, t(161)=2.17$, $p<0.05$. This interaction was plotted to explore whether it was in the hypothesized direction.

As displayed in Figure 2, those low in Conscientiousness and high in Neuroticism (insecure and impulsive types) reported fewer friends than those low in Conscientiousness and low in Neuroticism. This result was contrary to hypotheses but simple slope analyses were not significant.

\section{Discussion}

This study aimed to explore the effect of FFM traits, including types based on these traits [10] [13], and self-esteem, narcissism, loneliness, shyness and boredom proneness. The study also compared predictors of Facebook use among university students and non-students.

Contrary to prediction, the three-way interaction of E, N, and C did not significantly predict Facebook usage patterns. Notably however, combination of these traits was tested in the form of a continuous variable interacttion rather than using an ANOVA approach with eight discrete types, which has been the predominant approach

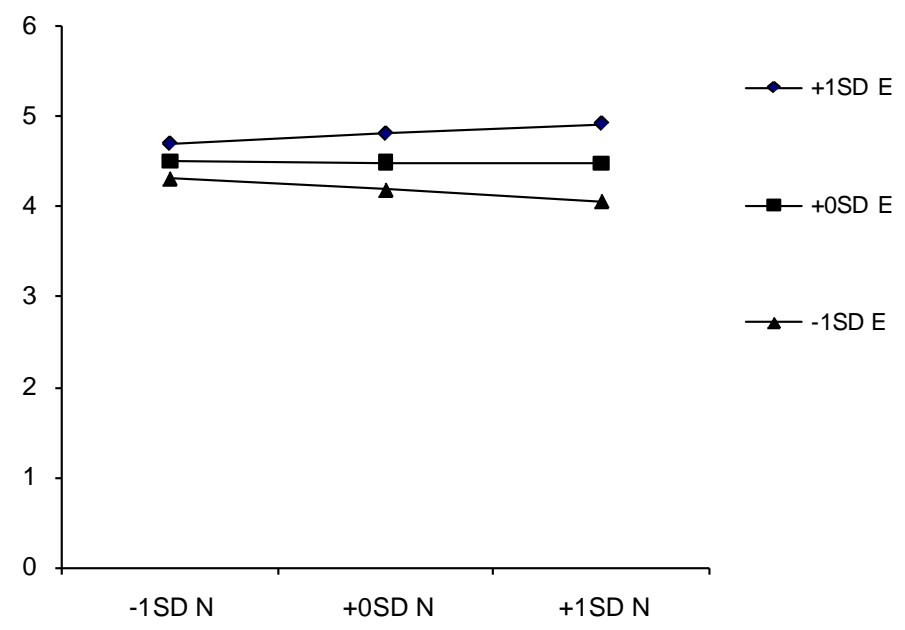

Figure 1. Plot of the two-way interaction between Neuroticism and Extraversion for number of Facebook friends for students. $\mathrm{N}=\mathrm{Neu}-$ roticism, $\mathrm{E}=$ Extraversion. 


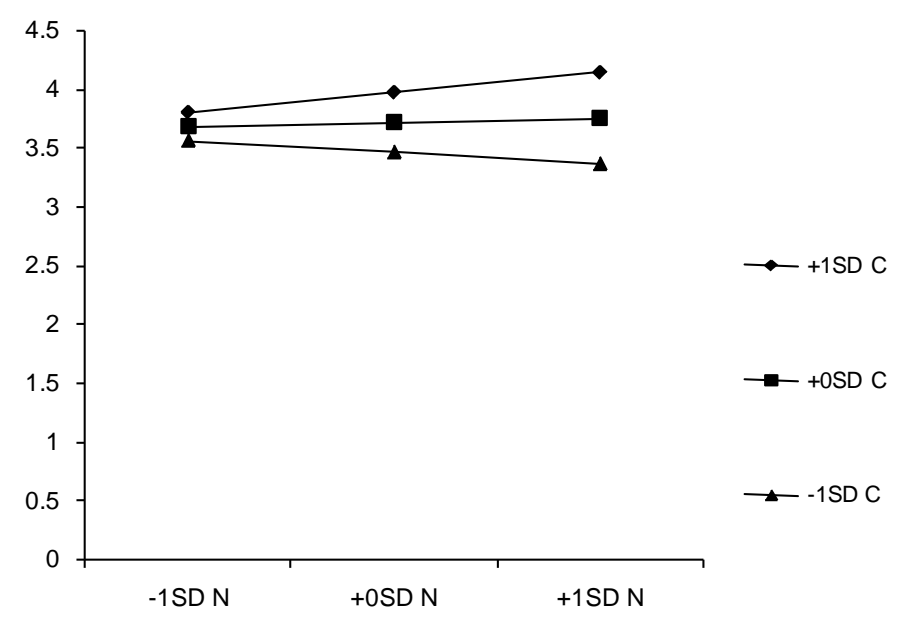

Figure 2. Plot of the two-way interaction between Neuroticism and Conscientiousness for number of Facebook friends for non-students. $\mathrm{N}$ = Neuroticism, $\mathrm{C}=$ Conscientiousness.

in previous research. The current approach was selected on the basis that a researcher-driven classification may not accurately represent the variability in personality types in the data. Notably, continuous variable interactions are difficult to detect due to statistical power [26]. Future research could use statistically driven techniques such as cluster analysis to form personality types from scores on the three personality traits [27], and determine whether these are linked to Facebook use.

Exploratory plots of significant two-way interactions indicated that high Extraversion-high Neuroticism students tended to have more friends compared to those who were low in Neuroticism and high on Extraversion. It may be that highly extraverted students are anxious about their friendships and add or accept friendship requests from others to monitor them more closely. Non-students low in Conscientiousness and high in Neuroticism had fewer friends, than those low in Neuroticism. These individuals may not make the effort to seek or invest in Facebook friendships due to anxiety or self-consciousness. Although Neuroticism did not have a significant direct effect on Facebook use, Neuroticism does appear to interact with other personality traits, suggesting that future research should continue to investigate the effect of combinations of traits on Facebook use.

This study was the first to include self-esteem, narcissism, loneliness, shyness and boredom proneness alongside FFM traits in the prediction of Facebook use. Consistent with Ryan and Xenos [2], students and non-students who were higher on narcissism reported spending significantly more time on their Facebook profiles daily. Narcissists may spend longer on Facebook in order to control their self-image and how they are perceived by others for the purpose of self-assurance [16]. The fact that Facebook is a popular communication tool for the narcissistic individual is not surprising, given narcissism is likely to be characterized by a range of loose networks, rather than smaller networks built on comprehensive relationships [16]. Agreeableness was the strongest predictor of daily logins for students and was negatively related to log-ins suggesting that antagonistic individuals may find it easier to communicate online. Narcissism was also the only significant predictor of daily logins for non-students (the overall model was non-significant for non-students). Again, logins may be motivated by narcissists' continual need to confirm self-worth; Facebook provides immediate feedback. Perhaps these individuals accumulate higher time spent online through shorter intervals of time online, but more frequent logins. This is plausible given the results also showed that SmartPhones and SmartBooks are popular ways of accessing Facebook.

Finally, this was the first study to examine the influence of boredom proneness on Facebook use, with previous studies employing single items to capture boredom. Boredom was weakly, positively correlated with time spent online but was unrelated to other usage variables. Perhaps individuals who access Facebook due to boredom do so via SmartPhones and SmartBooks only. This was not examined.

This study relied upon self-report measures of Facebook usage, and more valid data could be attained by objectively coding and scoring Facebook profiles [28] or via direct observation. There is a lack of theoretical and practical guidance in operationalizing Facebook use, which continually limits research findings [8]. Quantitative 
variables such as time, number of friends, number of logins and number of photos may not be reliable indicators of Facebook use, and qualitative data might be more informative with regard to meaningful variation in usage aspects. Narcissism could be investigated with reference to its impact on type (i.e. self or others) rather than number of photos for example. In addition, Facebook researchers need to be mindful that the communicative functions of Facebook continue to evolve and ideally should collect longitudinal usage data. This would also provide an understanding of how people edit or change their profiles over time, which may reflect how they are thinking and feeling at a particular time.

This study also found that university students spend a considerable amount of time on Facebook per day. Thus, researchers need to explore potential positive or negative effects of Facebook on learning [8] [29]. Little is known about the effects of Facebook use on student engagement and academic performance.

The findings from this study suggest that Narcissism was the strongest predictor of time spent on Facebook per day for both students and non-students. Narcissism was also the strongest predictor of number of daily logins for non-students, however agreeableness was the strongest predictor for students. Extraversion was the strongest predictor of number of Facebook friends for both students and non-students. The interaction of Extraversion and Neuroticism was also a predictor of Facebook friends for students, and the interaction of Extraversion and Conscientiousness for non-students. Knowledge about how different personalities use Facebook could further enhance the online experience, to benefit both the consumer and the organization.

\section{References}

[1] Ellison, N.B., Steinfield, C. and Lampe, C. (2007) The Benefits of Facebook "Friends": Social Capital and College Students’ Use of Online Social Network Sites. Journal of Computer-Mediated Communication, 12, 1143-1168. http://dx.doi.org/10.1111/j.1083-6101.2007.00367.x

[2] Ryan, T. and Xenos, S. (2011) Who Uses Facebook? An Investigation into the Relationship between the Big Five, Shyness, Narcissism, Loneliness, and Facebook Usage. Computers in Human Behavior, 27, 1658-1664. http://dx.doi.org/10.1016/j.chb.2011.02.004

[3] Kalpidou, M., Costin, D. and Morris, J. (2011) The Relationship between Facebook and the Well-Being of Undergraduate College Students. Cyberpsychology, Behavior and Social Networking, 14, 183-189. http://dx.doi.org/10.1089/cyber.2010.0061

[4] Moore, K. and McElroy, J.C. (2012) The Influence of Personality on Facebook Usage, Wall Postings, and Regret. Computers in Human Behavior, 28, 267-274. http://dx.doi.org/10.1016/j.chb.2011.09.009

[5] Costa, P.T. and McCrae, R.R. (1992) Revised NEO Personality Inventory (NEO-PI-R) and the NEO Five-Factor Inventory (NEO-FFI): Professional Manual. Psychological Assessment Resources Inc., Odessa.

[6] Amichai-Hamburger, Y. and Vinitzky, G. (2010) Social Network Use and Personality. Computers in Human Behavior, 26, 1289-1295. http://dx.doi.org/10.1016/j.chb.2010.03.018

[7] Ross, C., Orr, E.S., Sisic, M., Arseneault, J.M., Simmering, M.G. and Orr, R.R. (2009) Personality and Motivations Associated with Facebook Use. Computers in Human Behavior, 25, 578-586. http://dx.doi.org/10.1016/j.chb.2008.12.024

[8] Skues, J.L., Williams, B. and Wise, L. (2012) The Effects of Personality Traits, Self-Esteem, Loneliness, and Narcissism on Facebook Use among University Students. Computers in Human Behavior, 28, 2414-2419. http://dx.doi.org/10.1016/j.chb.2012.07.012

[9] Wilson, K., Fornasier, S. and White, K.M. (2010) Psychological Predictors of Young Adults’ Use of Social Networking Sites. Cyberpsychology, Behavior and Social Networking, 13, 173-177. http://dx.doi.org/10.1089/cyber.2009.0094

[10] Torgersen, S. (1995) Personlighet og personlighetsforstyrrelser. Universitetetsforlaget, Oslo.

[11] Vollrath, M. and Torgersen, S. (2002) Who Takes Health Risks? A Probe into Eight Personality Types. Personality and Individual Differences, 32, 1185-1197.http://dx.doi.org/10.1016/S0191-8869(01)00080-0

[12] Grant, S. and Langan-Fox, J. (2006) Occupational Stress, Coping and Strain: The Combined/Interactive Effect of the Big Five Traits. Personality and Individual Differences, 41, 719-732. http://dx.doi.org/10.1016/j.paid.2006.03.008

[13] Vollrath, M. (2000) Personality Types and Coping. Personality and Individual Differences, 29, 367-378. http://dx.doi.org/10.1016/S0191-8869(99)00199-3

[14] Gonzales, A.L. and Hancock, J.T. (2011) Mirror, Mirror on My Facebook Wall: Effects of Exposure to Facebook on Self-Esteem. Cyberpsychology, Behavior and Social Networking, 14, 79-83. http://dx.doi.org/10.1089/cyber.2009.0411

[15] Buffardi, L.E. and Campbell, W.K. (2008) Narcissism and Social Networking Web Sites. Personality \& Social Psychology Bulletin, 34, 1303-1314. http://dx.doi.org/10.1177/0146167208320061 
[16] Mehdizadeh, S. (2010) Self-Presentation 2.0: Narcissism and Self-Esteem on Facebook. Cyberpsychology, Behavior and Social Networking, 13, 357-364.

[17] Orr, E.S., Sisic, M., Ross, C., Simmering, M.G., Arseneault, J.M. and Orr, R.R. (2009) The Influence of Shyness on the Use of Facebook in an Undergraduate Sample. Cyberpsychology \& Behavior: The Impact of the Internet, Multimedia and Virtual Reality on Behaviour and Society, 12, 337-340. http://dx.doi.org/10.1089/cpb.2008.0214

[18] Pempek, T.A., Yermolayeva, Y.A. and Calvert, S.L. (2009) College Students' Social Networking Experiences on Facebook. Journal of Applied Developmental Psychology, 30, 227-238. http://dx.doi.org/10.1016/j.appdev.2008.12.010

[19] Murray, G., Judd, F., Jackson, H., Fraser, C., Komiti, A., Robins, G., Pattison, P., et al. (2009) Personality for Free : Psychometric Properties of a Public Domain Australian Measure of the Five-Factor Model Australian Measure of the Five-Factor Model. Australian Journal of Psychology, 61, 167-174. http://dx.doi.org/10.1080/00049530802326784

[20] Rosenberg, M. (1965) Society and the Adolescent Self-Image. Princeton University Press, Princeton.

[21] Ames, D.R., Rose, P. and Anderson, C.P. (2006) The NPI-16 as a Short Measure of Narcissism. Journal of Research in Personality, 40, 440-450. http://dx.doi.org/10.1016/j.jrp.2005.03.002

[22] Russell, D.W., et al. (1996) UCLA Loneliness Scale Version 3: Reliability, Validity and Factor Structure. Journal of Personality Assessment, 51, 20-40. http://dx.doi.org/10.1207/s15327752jpa6601_2

[23] Farmer, R. and Sundberg, N.D. (1986) Boredom Proneness: The Development and Correlates of a New Scale. Journal of Personality Assessment, 50, 4-17. http://dx.doi.org/10.1207/s15327752jpa5001 2

[24] Cheek, J.M. (1983) The Revised Cheek and Buss Shyness Scale. Unpublished Manuscript, Wellesley College, Wellesley.

[25] Coxe, S., West, S.G. and Aiken, L.S. (2009) The Analysis of Count Data: A Gentle Introduction to Poisson Regression and Its Alternatives. Journal of Personality Assessment, 91, 121-136. http://dx.doi.org/10.1080/00223890802634175

[26] Tabachnick, B.G. and Fidell, L.S. (2007) Using Multivariate Statistics. 5th Edition, Allyn \& Bacon, New York.

[27] Aldenferder, M. and Blashfield, R. (1984) Cluster Analysis. Sage Publications, Beverly Hills.

[28] Zhao, S., Grasmuck, S. and Martin, J. (2008) Identity Construction on Facebook: Digital Empowerment in Anchored Relationships. Computers in Human Behaviour, 24, 1816-1836. http://dx.doi.org/10.1016/j.chb.2008.02.012

[29] Junco, R. (2012) Too Much Face and Not Enough Books: The Relationship between Multiple Indices of Facebook Use and Academic Performance. Computers in Human Behavior, 28, 187-198. http://dx.doi.org/10.1016/j.chb.2011.08.026. 
Scientific Research Publishing (SCIRP) is one of the largest Open Access journal publishers. It is currently publishing more than 200 open access, online, peer-reviewed journals covering a wide range of academic disciplines. SCIRP serves the worldwide academic communities and contributes to the progress and application of science with its publication.

Other selected journals from SCIRP are listed as below. Submit your manuscript to us via either submit@scirp.org or Online Submission Portal.
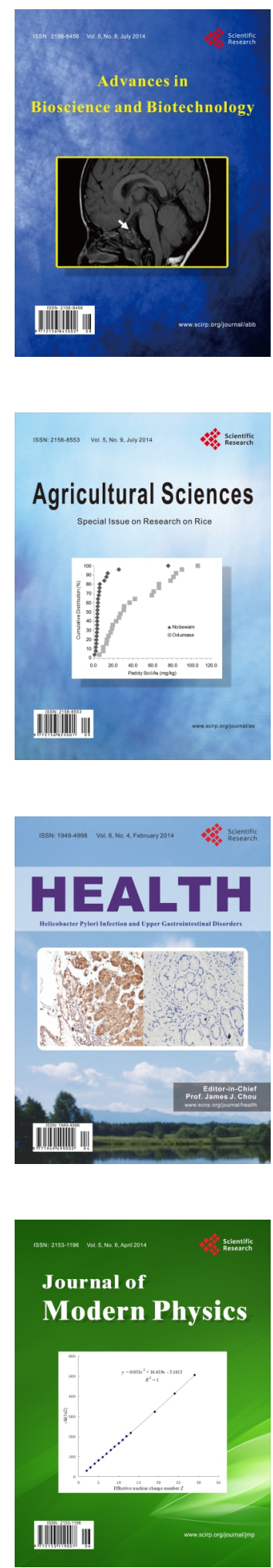
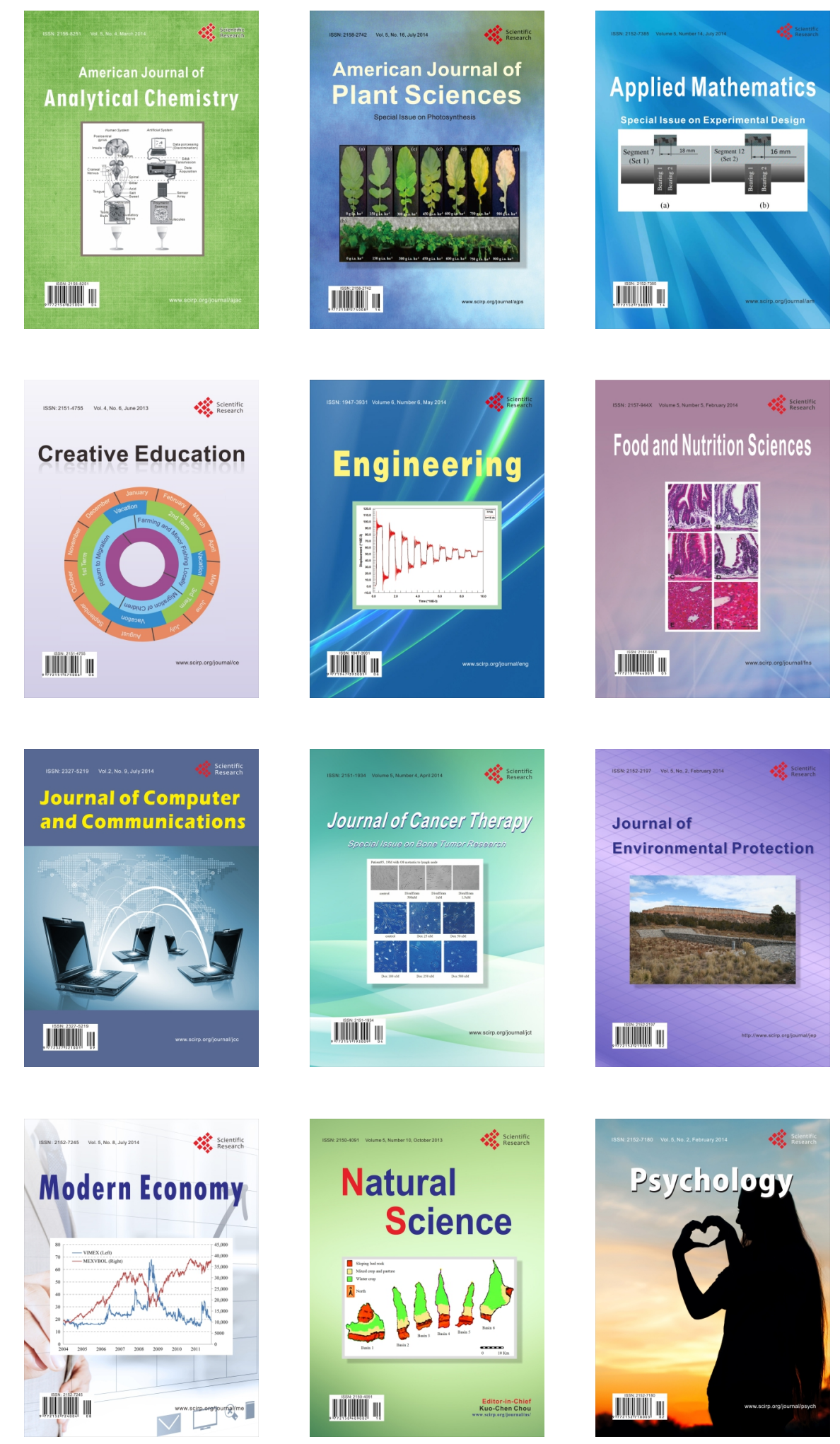